\title{
Removal of copper by calcium alginate encapsulated magnetic sorbent
}

\author{
Soh-Fong Lim ${ }^{\mathrm{a}, \mathrm{b}}$, Yu-Ming Zheng ${ }^{\mathrm{a}}$, Shuai-Wen Zou ${ }^{\mathrm{a}}$, J. Paul Chen ${ }^{\mathrm{a}, *}$ \\ a Division of Environmental Science and Engineering, National University of Singapore, 10 Kent Ridge Crescent, Singapore 119260, Singapore \\ ${ }^{\mathrm{b}}$ Department of Chemical and Biomolecular Engineering, National University of Singapore, 10 Kent Ridge Crescent, Singapore 119260, Singapore
}

\section{A R T I C L E I N F O}

\section{Article history:}

Received 6 June 2008

Received in revised form 13 May 2009

Accepted 17 May 2009

\section{Keywords:}

Calcium alginate encapsulated magnetic sorbent

Copper sorption

Equilibrium

Kinetics

Modeling

\begin{abstract}
A B S T R A C T
In this study, the adsorption performance of copper on calcium alginate encapsulated magnetic sorbent is investigated via equilibrium and kinetics study. Results showed the sorption performance is greatly affected by the initial solution $\mathrm{pH}$, the background ionic strength, the mechanical stirring speed, and the presence of humic acid. The optimum copper sorption was achieved at initial solution $\mathrm{pH}>5$. The copper uptake is poor in the presence of higher background ionic strength (sodium perchlorate). Langmuir equation can be well used to describe the adsorption isotherm data. The maximum sorption capacity $\left(q_{\max }\right)$ and Langmuir constant $(b)$ decrease from 60 to $49 \mathrm{mgg}^{-1}$ and 1.43 to $0.35 \mathrm{~L} \mathrm{mg}^{-1}$ as the ionic strength is increased from 0 to $0.05 \mathrm{M}$. Kinetics study shows the sorption equilibrium can be obtained within $3 \mathrm{~h}$, and the adsorption kinetics data are well described by the intraparticle pore diffusion model. The mechanical stirring speed greatly enhances the mass transfer rate of copper ions onto the sorbent, and the external mass transfer coefficient $\left(k_{\mathrm{f}}\right)$ increases from $2.5 \times 10^{-5}$ to $2.5 \times 10^{-4} \mathrm{~m} \mathrm{~s}^{-1}$ when stirring speed is increased from 120 to $220 \mathrm{rpm}$. The presence of humic acid decreases the $k_{\mathrm{f}}$ from $2.10 \times 10^{-4}$ to $5 \times 10^{-5} \mathrm{~m} \mathrm{~s}^{-1}$, and increases the time for copper to attain adsorption equilibrium due to clogging of surface pore which apparently reduce the surface reaction site.
\end{abstract}

(c) 2009 Elsevier B.V. All rights reserved.

\section{Introduction}

Adsorption has been extensively studied as a cost-effective technology for the removal of heavy metals from wastewater during the past decades [1-4]. Sorbent plays a key role in the removal of water contaminants since it determines the performance of treatment technology, including adsorption capacity and post-treatment (separation).

In recent years, the magnetic sorption technology has become one of the emerging technologies in solving environmental problems due to its high efficiency and ease in post-treatment/separation. Some of its applications include iron oxides for desalination [5], magnetic filtration for separation of flocs [6], and iron powder for removal of oil from feathers [7].

The technology has attracted much attention in the area of water treatment [8]. The magnetic sorbents behave similar to or even better than various commercial adsorbents [9]. After the usage, the magnetic sorbent can be easily separated from the solution by simple magnetic force. In the literature, iron oxides have been found to be successfully used as composite materials with host materials in fabricating magnetic sorbent [10-13]. The main advantages of using iron oxides as composite materials with host materials are

\footnotetext{
* Corresponding author. Fax: +65 6872 5483/1 8313038636.

E-mail addresses: esecjp@nus.edu.sg, jchen.enve97@gtalumni.org (J.P. Chen).
}

the high porosity, magnetic property, and sometimes good settling property $[8,9]$. Since surface functional group reactions are involved in the sorption processes, higher content of surface functional group sites in a sorbent would greatly lead to higher sorption capacity for removal of contaminants. The host materials to support iron oxides are used to overcome the foregoing problems. The potential host materials are zeolite, alginate, chitosan, clay, and activated carbon [10-13]. Clay-iron oxide magnetic composites and magnetic zeolites were successfully synthesized and used for the removal of metallic contaminants from wastewater and drinking water $[10,11]$. Some recent studies on cations removal have demonstrated that magnetic chitosan nanoparticles can be good sorbents for gold, $\mathrm{Au}(\mathrm{III})$ and cobalt, $\mathrm{Co}(\mathrm{II})$ with the maximum adsorption capacities of 59.52 and $27.5 \mathrm{mg} \mathrm{g}^{-1}$, respectively $[12,13]$.

However, few reports are available on the fabrication of composite magnetic sorbent for copper removal. In our recent study, calcium alginate magnetic sorbent was developed to remove metal ions. The resulting magnetic sorbent was able to remove substantial amount of copper [14,15]. In another study in literature, micro-size magnetic polymer adsorbent coupling with metal chelating ligands of iminodiacetic acid was found to be able to load $7.68 \mathrm{mg} \mathrm{g}^{-1}$ of copper ions [16]. These promising findings have laced an alternative solution for the removal of copper from contaminated water using magnetic adsorption technology. Thus, a comprehensive investigation on the sorption behavior of copper on magnetic sorbent is needed. 